\title{
METABOLIC EQUIVALENT OF BRISK WALKING AND PLAYING NEW GENERATION ACTIVE COMPUTER GAMES IN YOUNG-ADULTS
}

\author{
Mark ET Willems $^{(\mathrm{A}, \mathrm{C}, \mathrm{D}, \mathrm{E}, \mathrm{F})}$, Timothy S Bond ${ }^{(\mathrm{A}, \mathrm{B}, \mathrm{C}, \mathrm{D}, \mathrm{F})}$ \\ Faculty of Sport, Education \& Social Sciences, University of Chichester, College Lane, Chichester, United \\ Kingdom
}

\begin{abstract}
Introduction: Regular moderate-intensity exercise, such as brisk walking, provides health benefits. We compared the energy expenditure during brisk treadmill walking and playing new generation active computer games (i.e. Nintendo Wii Sports tennis, baseball and boxing).

Methods: Ten participants (mean $\pm S D, 21 \pm 1$ years; $73.9 \pm 12.0 \mathrm{~kg} ; 1.76 \pm 0.06 \mathrm{~m}$ ) walked at a brisk pace on a treadmill ( $3 \times 10 \mathrm{~min}, 5 \mathrm{~min}$ rest periods) or played tennis, baseball and boxing (Wii sports) in similar time sequence. Energy expenditure was measured with the portable Cosmed $\mathrm{K} 4 b^{2}$ indirect calorimetry system and expressed in metabolic equivalents (METs). A within-subjects crossover design was used with repeated measures two-way ANOVA and post-hoc paired samples t-test for analysis.

Results: METs during brisk treadmill walking $(5.7 \pm 1.2$ range: $4.4-8.5)$ were significantly higher $(P<0.05)$ than during

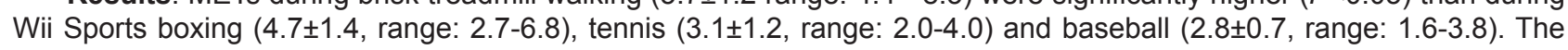
MET values of boxing were higher than for tennis and baseball $(P<0.05)$.

Conclusions: Guidelines for physical activity required to get health benefits could be met by young adults playing Wii Sports but are activity-specific. Playing a combination of Wii Sports tennis, baseball, and boxing may not necessarily be a substitute for a moderate-intensity exercise session as part of a programme to promote and maintain health.
\end{abstract}

Key words: indirect calorimetry, public health, boxing, brisk walking, video games

\section{Introduction}

Physical inactivity is linked to major health problems in modern society such as obesity, type 2 diabetes and cardiovascular diseases (1). Health benefits by physical activity for adults aged 18-65 yrs are achieved with at least $30 \mathrm{~min}$ of moderate-intensity physical activity on five or more days of the week, with the exercise of one session performed in several bouts of at least $10 \mathrm{~min}(2)$.

The classification of various physical activities and their intensity for adults is listed in the compendium of physical activities (3). Health professionals can use the coding scheme to identify examples of moderate-intensity physical activities. In this scheme, classification of physical activities is based on energy expenditure as a multiple of resting metabolic rate while sitting (i.e. metabolic equivalent or MET) (4). Physical activities are considered light (i.e. $<3$ METs), moderate (i.e. 3-6 METs) or vigorous (i.e. $>6 \mathrm{METs}$ ). Brisk walking at 5.6 $\mathrm{km} \cdot \mathrm{h}^{-1}$, for example, is a 3.8 METs activity (3) and thus an activity of moderate-intensity. Brisk walking for 3 bouts of $10 \mathrm{~min}$ in one session should meet current recommendations but actual MET values of physical activities may vary from person to person (2).

Recently, the popularity of new generation active screen games may offer an opportunity to increase physical activity levels of the general population. Active games, such as Nintendo Wii, Sony EyeToy ${ }^{\mathrm{TM}}$, and Dance Simulation stimulate interaction and whole body movement during game play. Studies have focussed primarily on the energy expenditure of interactive game play or activity promoting games in children and adolescents (5-12) and only a few in young-adults (13-15).

A recent study reported that the energy expenditure playing new generation active computer games was less than with playing the sport itself, although the authors recognized that the measurement device in their study did not detect arm movements well (7). Whether a session of new generation active computer games in young-adults with significant arm movements would meet recommended physical activity guidelines is not known. In addition, differences in individual physiological responses to physical activity (2) would require a comparison of a recommended exercise that provides health benefits with interactive game play in the same individuals but such studies have not been done yet.

Therefore, the aim of the present study was to examine energy expenditure during new generation active computer games versus a traditional physical activity in young adults. 


\section{Methods}

\section{Participants and settings}

A convenience sample of seven male and three female students (age: $21.0 \pm 1.0 \mathrm{yr}$, body mass: 73.9 $\pm 12.0 \mathrm{~kg}$, height: $1.76 \pm 0.06 \mathrm{~m}$, body mass index: $23.7 \pm 3.3 \mathrm{~kg} \cdot \mathrm{m}^{-2}$ ) from the University of Chichester participated and provided written informed consent. The study protocol was approved by the University of Chichester's Ethics Committee. Height and body mass was measured to the nearest $0.1 \mathrm{~cm}$ and 0.1 $\mathrm{kg}$, respectively, with participants lightly clothed but shoeless. Body mass index (BMI) was calculated as body mass $(\mathrm{kg})$ divided by height squared $\left(\mathrm{m}^{2}\right)$. Based on BMI values, one male and two females were considered overweight (i.e. BMI between 25.0 and 29.9). All testing was performed in an Exercise Physiology laboratory at the University of Chichester.

\section{Design of the study}

Each participant performed a testing session on separate days with either playing on the Nintendo Wii Sports (i.e. tennis, baseball and boxing) following brief practice or treadmill walking. The Nintendo Wii Sports is an interactive video game in which the player employs a wireless handheld remote controller that senses player movement and translates them into animated caricature screen movements. Each sport was played for $10 \mathrm{~min}$ with a $5 \mathrm{~min}$ rest between sports (Table 1) as this time protocol meets the minimum recommendation for duration of each bout of exercise when performed according to guidelines of physical activity for health (2) with the chosen rest period to ensure that the physiological responses in a $10 \mathrm{~min}$ bout were the result of each bout of game play. Total play time was chosen to meet recommendations for $30 \mathrm{~min}$ as a minimum requirement for physical activity in one session (2). Six participants were novice and the remaining four had limited experience on Nintendo Wii Sports. All participants started at the easiest level of competition and the points earned during the games dictated the progress in the game. Participants played at their own level of game play against central processing unit opponents and received no verbal encouragement. Testing order of playing sports was not randomised. In the walking session, participants walked briskly at a self-selected pace on a treadmill (Woodway Ergo ELG 70, Cranlea and Co., Birmingham, UK) (walking speed $6.1 \pm 0.6 \mathrm{~km} \cdot \mathrm{h}^{-1}$, range: 5.0-7.5). Self-paced walking and self-selected game play ensures ecological validity of the study. Time sequence of the walking session, i.e. walks and rest periods, was similar as the time sequence of the session playing sports (Table 1) with at least one day between testing sessions.
Table 1. Time sequence for testing

\begin{tabular}{|c|c|c|c|c|c|}
\hline $\begin{array}{c}\text { Session } \\
1\end{array}$ & $\begin{array}{c}\text { Brisk } \\
\text { walk }\end{array}$ & Rest & $\begin{array}{c}\text { Brisk } \\
\text { walk }\end{array}$ & Rest & $\begin{array}{c}\text { Brisk } \\
\text { walk }\end{array}$ \\
\hline $\begin{array}{c}\text { Session } \\
2\end{array}$ & $\begin{array}{c}\text { Wii } \\
\text { tennis }\end{array}$ & Rest & $\begin{array}{c}\text { Wii ba- } \\
\text { seball }\end{array}$ & Rest & $\begin{array}{c}\text { Wii } \\
\text { boxing }\end{array}$ \\
\hline $\begin{array}{c}\text { Time } \\
(\mathrm{min})\end{array}$ & $0-10$ & $10-15$ & $15-25$ & $25-30$ & $30-40$ \\
\hline
\end{tabular}

\section{Energy expenditure}

Energy expenditure was measured with a portable metabolic system (Cosmed $\mathrm{K} 4 b^{2}$, Cosmed, Rome, Italy). Calibration of the Cosmed $\mathrm{K} 4 b^{2}$ was conducted on each testing day according to the manufacturer's guidelines with standard gases of known concentrations (oxygen, $\mathrm{O}_{2}: 14.60 \%$, carbon dioxide, $\mathrm{CO}_{2}$ : $5.99 \%)$. Respiratory volume was calibrated using a $3 \mathrm{~L}$ volume syringe. A delay calibration was used in order to match the changes in fractions of expired oxygen (i.e. $\mathrm{F}_{\mathrm{E}} \mathrm{O}_{2}$ ) and fractions of expired carbon dioxide (i.e. $\left.\mathrm{F}_{\mathrm{E}} \mathrm{CO}_{2}\right)$. Finally, a room air measurement calibration was also conducted before each testing session. The Cosmed $\mathrm{K} 4 b^{2}$ has been previously used for measurement of energy expenditure (17). One metabolic equivalent equals a metabolic rate of $3.5 \mathrm{mlO}_{2} \cdot \mathrm{kg} \cdot \mathrm{min}^{-1}$ (4). MET values from the Cosmed $\mathrm{K} 4 b^{2}$ were averaged for each 10 min activity.

\section{Statistical analysis}

SPSS 15.0 for Windows was used for statistical analyses (i.e. repeated measures two-way ANOVA with post-hoc paired samples t-test) to determine differences in METs between brisk treadmill walking and playing each sport at similar time intervals in each testing session, between 10 min bouts of walking or sports in one session and between playing each sport in each testing session. Significance level was set at $P$ $<0.05$.

\section{Results}

All participants had METs higher than three during brisk treadmill walking (range: 4.4-8.5) (Figure 1) with $30 \%$ of the participants METs values higher than six (i.e. vigorous intensity exercise) for the $1^{\text {st }} 10 \mathrm{~min}$ of walking and $20 \%$ of those participants METs values higher than six (i.e. vigorous intensity exercise) for the $2^{\text {nd }}$ and $3^{\text {rd }}$ bout of walking (Figure 1). Metabolic equivalents of the 3 bouts of 10 min brisk treadmill walking were similar (Figure 2, $P>0.05$ ) indicating similar oxygen consumption over time. Metabolic equivalent values for tennis and baseball between three and six (i.e. moderate intensity exercise) were obtained by $50 \%$ and $40 \%$ of the participants, respectively (Figure 1). 


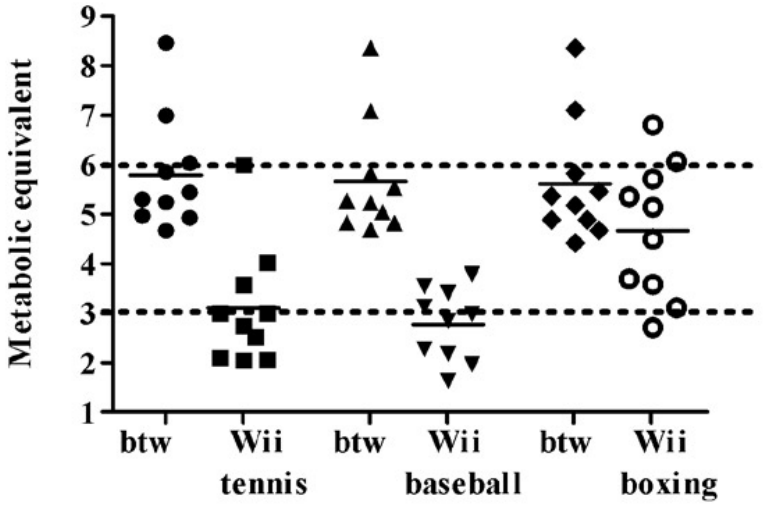

Activity

Fig. 1. Energy expenditure of all participants $(n=10)$, expressed as metabolic equivalent, during brisk treadmill walking (btw) and Nintendo Wii game Wii Sports (tennis, baseball and boxing). The following order of activities was done in two sessions: 0-10 min (btw or tennis), 5 min rest, 15-25 min (btw or baseball, $5 \mathrm{~min}$ rest, 30-40 $\mathrm{min}$ (btw or boxing). Short-dashed horizontal lines indicate a MET of 3.0 (i.e. moderate intensity exercise) and 6.0 (i.e. vigorous intensity exercise). Solid horizontal lines within the data of each activity represent the mean $M E T$ value

The MET for boxing was higher than tennis and baseball (Figure 2, $P<0.05$ ) with $70 \%$ of the participants with METs between three and six (i.e. moderate intensity exercise) and two participants METs higher than six (i.e. vigorous intensity exercise). The metabolic equivalents of playing tennis (3.1 $\pm 1.2 \mathrm{METs})$, baseball (2.8 \pm 0.7 METs) and boxing $(4.7 \pm 1.4$ METs) were 2.6, 2.9 and 1.0 METs lower than the METs for brisk treadmill walking (Figure 2, $P<0.05$ ). One participant had METs during playing tennis, baseball and boxing always below three (i.e. light intensity exercise) (Figure 1).

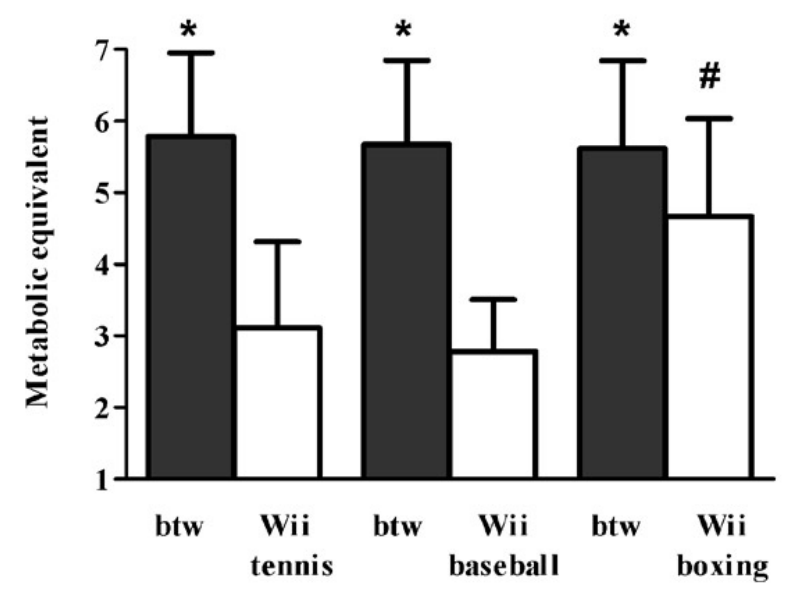

Activity

Fig. 2. Energy expenditure, expressed as metabolic equivalent, during brisk treadmill walking (btw) and Nintendo Wii game Wii Sports (tennis, baseball and boxing). Data of 10 participants are expressed as mean $\pm S D$. The following order of activities was done in two sessions: 0-10 min (btw or tennis), 5 min rest, 15-25 min (btw or baseball, 5 min rest, 30-40 min (btw or boxing). ${ }^{*}$, indicates significant different between btw and Wii activity $(P<$ 0.05). \#, indicates significant difference between Wii boxing and Wii tennis and baseball, respectively, $P<0.05$ )

\section{Discussion}

We examined the energy expenditure during the new generation active computer game Nintendo Wii Sports versus a traditional physical activity of moderate-intensity. Participants were purposely selected to be young adults because the energy expenditure in the compendium of physical activities is based on an adult population (3) and the recommendations of physical activity to promote and maintain health by Haskell et al (2) are for healthy aged adults 18-65 years. Therefore, a comparison of our results with other studies on interactive game play in children and adolescents is not made. In addition, a comparison with other studies using adult subjects is complicated as other factors such the competitiveness of the testing environment and 'intensity' of the arm movements may influence the metabolic responses. The potential effect of such factors may warrant future studies on interactive game play.

In the present study, the comparison for energy expenditure was made between brisk treadmill walking and playing Nintendo Wii Sports (i.e. tennis, baseball and boxing). Both brisk walking speed and style of playing Wii Sports were self-selected by each participant. Although this may be considered a potential weakness of the present study, it ensures ecological validity. Wii Sports were also not played in random order but oxygen uptake returned back close to pre-exercise levels between bouts of treadmill walking and playing various sports (unpublished observations) indicating no effect of preceding exercise on energy expenditure during activity. However, the small sample size $(\mathrm{n}=10)$ in the present study should be recognized. In addition, it needs to be acknowledged that none of the participants could be considered an experienced game player on the Nintendo Wii Sports. Playing experience has been shown to play a role in energy expenditure with some games such as Dance Dance Revolution (13) and experience of playing the Nintendo Wii Sports may influence energy expenditure as well.

Participants did not feel restricted during active computer game play by wearing the Cosmed $\mathrm{K} 4 b^{2}$. Although the Cosmed $\mathrm{K} 4 b^{2}$ captures energy costs of whole body movements and has been used in previous studies (16), this system may overestimate oxygen uptake values at high intensities (17). However, we felt that the Cosmed $\mathrm{K} 4 b^{2}$ was appropriate for our study to measure energy expenditure as the intensity of activity was mostly lower than 6 METs. All participants had METs higher than 3.0 during brisk walking, meeting the minimum required intensity for a physical activity session that is part of a regular physical activity programme to provide health gains. This observation may suggest that all individuals made an appropriate effort to exercise, at least by treadmill walking. Some participants had METs higher than 6.0 during brisk walking, 
an intensity considered vigorous. When combining the energy expenditure of moderate and vigorous intensity activities, the aim is to achieve between 450 and 750 MET $\cdot \mathrm{min} \cdot \mathrm{wk}^{-1}$ for health gains (2). All our participants would meet $750 \mathrm{MET} \cdot \mathrm{min} \cdot \mathrm{wk}^{-1}$ with less than $6,30 \mathrm{~min}$ brisk walking sessions per week (range 3.0-5.3 sessions). However, when a calculation of achieved METs is done for a combined session of playing tennis, baseball and boxing (only taking into account when the average MET over 10 min was above 3.0), only 4 participants would be able to meet the recommendations within one week with no more than one session a day. Therefore, a combined session of playing tennis, baseball and boxing does not necessarily meet the guidelines for a physical activity session done for health reasons. Although boxing had the highest energy expenditure, only $60 \%$ of the participants would have met the activity guidelines with less than 7, $30 \mathrm{~min}$, sessions per week. Finally, the metabolic equivalent, although a widely used physiological concept, may underestimate the real energy cost (18). However, the purpose of our study was a comparison of METs between a traditional physical activity and new generation active computer games and not aimed to measure real energy cost of these activities. In addition, this study does not provide information on choice of exercise modality and adherence by the participants when exercising for health. Further research is needed to compare the energy expenditure between active gaming and traditional physical activities in disease states such as obesity and Type 2 diabetes mellitus. In addition, prospective studies are required to examine the health benefits of interactive game play.

\section{Conclusion}

Playing a combination of Wii Sports tennis, baseball and boxing for $10 \mathrm{~min}$ each expended significant less energy than a brisk treadmill walk. Such combination of game playing in young-adults may not necessarily be sufficient to meet guidelines for physical activity of moderate-intensity that provides health benefits.

\section{Acknowledgement}

Purchase of the Cosmed $\mathrm{K} 4 b^{2}$ was made possible by funding from the Science Research Investment Fund, HEFCE, United Kingdom.

\section{References}

1. Booth FW, Lees SJ. Fundamental questions about genes, inactivity, and chronic diseases. Physiol Genomics 2007; 28: 146-57.

2. Haskell WL, Lee IM, Pate RR, et al. Physical activity and public health: updated recommendation for adults from the American College of Sports Medicine and the American Heart Association. Circulation 2007; 116: 1081-93.
3. Ainsworth BE, Haskell WL, Whitt MC, et al. Compendium of physical activities: an update of activity codes and MET intensities. Med Sci Sports Exerc 2000; 9: S498-S516.

4. Jetté M, Sidney K, Blümchen G. Metabolic equivalents (METS) in exercise testing, exercise prescription, and evaluation of functional capacity. Clin Cardiol 1990; 13: 555-65.

5. Epstein LH, Beecher MD, Graf JL, et al. Choice of interactive dance and bicycle games in overweight and nonoverweight youth Ann Behav Med 2007; 33: 124-31.

6. Graves LE, Ridgers ND, Stratton G. The contribution of upper limb and total body movement to adolescents' energy expenditure whilst playing Nintendo Wii. Eur J Appl Physiol 2008; 104: 617-23.

7. Graves L, Stratton G, Ridgers ND, et al. Energy expenditure in adolescents playing new generation computer games: cross-sectional study. BMJ 2007; 335: 1282-84.

8. Lanningham-Foster L, Jensen TB, Foster RC, et al. Energy expenditure of sedentary screen time compared with active screen time for children. Pediatrics 2006; 118: 1831-35.

9. Maddison R, Mhurchu CN, Jull A, et al. Energy expended playing video console games: an opportunity to increase children's physical activity? Pediatr Exerc Sci 2007; 19: 33443.

10. Ni Murchu C, Maddison R, Jiang Y, et al. Couch potatoes to jumping beans: A pilot study of the effect of active video games on physical activity in children. Int J Behav Nutr Phys Act 2008; doi: 10.1186/1479-5868-5-8.

11. Straker L, Abbott R. Effect of screen-based media on energy expenditure and heart rate in 9- to 12-year-old children. Pediatr Exerc Sci 2007; 19: 459-71.

12. Unnithan VB, Houser W, Fernall B. Evaluation of the energy cost of playing a dance simulation video game in overweight and non-overweight children and adolescents. Int J Sports Med 2006; 27: 804-9.

13. Sell K, Lillie T, Taylor J. Energy expenditure during physically interactive video game playing in male college students with different playing experience. J Am Coll Health 2008; 56: 50511.

14. Segal KR, Dietz WH. Physiologic responses to playing a video game. Am J Dis Child 1991; 145: 1034-6.

15. Tan B, Aziz AR, Chua K, et al. Aerobic demands of the dance simulation game. Int J Sports Med 2002; 23: 125-9.

16. Harrell JS, McMurray RG, Baggett CD, et al. Energy costs of physical activities in children and adolescents. Med Sci Sports Exerc 2005; 37: 329-36.

17. McNaughton LR, Sherman R, Roberts S, et al. Portable gas analyser Cosmed $\mathrm{K} \mathrm{b}^{2}$ compared to a laboratory based mass spectrometer system. J Sports Med Phys Fitness 2005; 45: 315-23.

18. Byrne NM, Hills AP, Hunter GR, et al. Metabolic equivalent: one size does not fit all. J Appl Physiol 2005; 99: 1112-19.

Received: March 13, 2009

Accepted: June 08, 2009

Published: June 10, 2009

Address for correspondence:

Faculty of Sport, Education \& Social Sciences

University of Chichester

College Lane Chichester

PO19 6PE United Kingdom

tel: $+44(0) 1243816468$

fax: $+44(0) 1243816080$

email: m.willems@chi.ac.uk

Timothy S. Bond: tbond84@hotmail.co.uk

\begin{tabular}{llll}
\hline Authors' contribution & B - Data Collection & D - Data Interpretation & F - Literature Search \\
A - Study Design & C - Statistical Analysis & E - Manuscript Preparation & G - Funds Collection
\end{tabular}

